\title{
Low-stress diamond films deposited on stainless steel by a two-step dropped power process in chemical vapor deposition
}

\author{
Xiao $\mathrm{Li}^{1}$, Jianqing Chen ${ }^{1}$, Jiansong $\mathrm{Ye}^{2}$, Tao Feng ${ }^{1}$, Xiaojun $\mathrm{Hu}^{1 *}$ \\ ${ }^{1}$ College of Materials Science and Engineering, Zhejiang University of Technology, \\ Hangzhou, 310014, China \\ ${ }^{2}$ Polytechnic Institute of Zhejiang University, Hangzhou, 310058, China
}

Abstract:

A continuous low-stress diamond film has been prepared on stainless steel by a novel two-step dropped power process using a $\mathrm{Cr} / \mathrm{CrN} / \mathrm{CrTiAlN}$ film as an interlayer. After the interlayer was deposited on the stainless steel, isolated diamond particles were firstly prepared under high power of $1800 \mathrm{~W}$ for $10 \mathrm{~min}$ in CVD, which has low stress, releasing most of thermal stress. Then, the low power of $1500 \mathrm{~W}$ was adopted to form continuous diamond films. The stress is obviously lower than that of the continuous diamond film deposited only in the first CVD process, indicating that the two-step dropped power process surely decreases the internal stress of the film. The blocky microstructure on sandblasted stainless steel and the existence of very small amount of pores in the diamond film are also beneficial to releases the stress.

Keywords: Diamond film; Interlayer; Stainless steel; Low stress

\section{Introduction}

Diamond is a kind of carbon material which has lots of outstanding chemical and physical properties, such as excellent corrosion resistance, extremely high thermal conductivity, biocompatibility, etc [1-3]. Stainless steel is a kind of important metal 
materials, which is widely used in food industry, medical apparatus and so on. Deposition of diamond coating on stainless steel can enhance the surface properties of steel and prolong its life. However, there exist two problems to successfully deposit diamond films on it. First, the graphitic soot is easily formed at the interface due to $\mathrm{Fe}$ atoms' catalytic effect, which leads to poor adhesion [4,5]. Second, the difference of thermal expansion coefficient (CTE) between diamond and stainless steel is very large, which results in the large internal stress and makes the film delaminate from the substrate easily [6,7]. To solve the problems, the introduction of an interlayer is an available method.

Up to now, many kinds of interlayers have been studied, such as $\mathrm{Cr}$ [8], Ti [8], Al [9], $\mathrm{Al} / \mathrm{W}$ [10], $\mathrm{Al} / \mathrm{AlN}$ [11], $\mathrm{CrN}$ [12-13], etc. These interlayers can serve as diffusion barriers, blocking $\mathrm{C}$ inward diffusion and $\mathrm{Fe}$ outward diffusion and continuous diamond film can be deposited on stainless steels. However, the prepared diamond film using the interlayer has large internal stress, which results in instability in the application and the film easily detaches from the substrate. Applying $\mathrm{Fe}_{2} \mathrm{~B}$ phase as an interlayer, the low-stress film was prepared, but its quality is poor [14]. Using a SiC layer by laser cladding as an interlayer, the stress is partly relaxed, but it is difficult to obtain a low stress diamond film [15]. In all, up to now, preparing low-stress diamond film on stainless steels is still very challenging. Therefore, it is significant to find a new interlayer and process to solve it.

It was shown that materials containing aluminum element could enhance diamond nucleation rate [9] and was beneficial to the deposition of diamond film. A 
$\mathrm{Cr} / \mathrm{CrN} / \mathrm{CrTiAlN}$ film is a kind of hard film which includes $\mathrm{Al}$ element. It has high toughness and high hardness [16], which can suppress the formation of crack and its propagation. It is advantageous to enhance the adhesion. So, in this work, the $\mathrm{Cr} / \mathrm{CrN} / \mathrm{CrTiAlN}$ film was selected as an interlayer.

Our previous study showed that the sandblasting pretreatment preferred to decrease the stress and improve the adhesion, but the stress is still high [17]. So, the sandblasting was used in the work and it still needs to look for other method to further decrease the stress. Generally, thermal stress is an important component in the stress of diamond films [13]. It is proportional to the temperature difference from deposition temperature to room temperature. In the experiment, high (low) deposition power means high (low) deposition temperature, which can produce large (small) stress. Therefore, it is anticipated that low stress diamond films can be obtained at low power. However, if the deposition power is very low, the deposition temperature will be too low to form diamond film. Our recent experiments show that the stress in the films is mainly related to the temperature when a continuous film forms, but not the temperature when diamond crystal nucleus form. So, we firstly used high power in CVD deposition to prepare isolated diamond particles to release the stress, and then we decreased the power to form continuous films. We call this process as two-step dropped power process.

\section{Experiment}

$3 \mathrm{Cr} 13$ stainless steels with dimensions of $20 \times 20 \times 2 \mathrm{~mm}^{3}$ were used as substrates in the experiment. In order to improve the adhesion, the substrates were firstly 
sandblasted, and the process parameters can be found in our previous publication [17]. Then the $\mathrm{Cr} / \mathrm{CrN} / \mathrm{CrTiAlN}$ interlayer was deposited on the substrates using a close field unbalance magnetron sputtering ion plating udp650 (Teer coatings Ltd). In the deposition, base pressure and working pressure are $1.3 \times 10^{-3}$ and $0.13 \mathrm{~Pa}$, respectively. Rotation speed of the substrate is $4 \mathrm{rev} / \mathrm{min}$ and bias voltage is $60 \mathrm{~V}$. The thicknesses of $\mathrm{Cr}$ film and $\mathrm{CrN} / \mathrm{CrTiAlN}$ layer are $\sim 0.2$ and $\sim 1.5 \mu \mathrm{m}$, respectively. In the deposition of CrN/CrTiAlN layer, $\mathrm{N}_{2}$ flow rate was gradually increased to the appropriate value. The currents for $\mathrm{Cr}$, $\mathrm{Ti}$ and $\mathrm{Al}$ target are 4, 6 and $6 \mathrm{~A}$, respectively. After that, the diamond film was deposited on the sample with the interlayer by HFCVD apparatus. In CVD process, the samples were firstly agitated for $30 \mathrm{~min}$ in slurry with a mixture of $20 \mathrm{ml}$ acetone, $0.2 \mathrm{~g}$ diamond particles (average diameter 0.1 $\mu \mathrm{m})$ and $0.2 \mathrm{~g}$ alumina powders (average diameter $63 \mu \mathrm{m}$ ). The working pressure is $1.6 \mathrm{kPa}$ in the deposition process. The bias current is $4 \mathrm{~A}$. In the first step, the power is set as $1800 \mathrm{~W}$ for $10 \mathrm{~min}$; in the second step, the power is decreased to $1500 \mathrm{~W}$. The deposition time is $20 \sim 120 \mathrm{~min}$. The carbon source is acetone, which is added into the reactor through the carrier gas $\mathrm{H}_{2}$. The flow ratio of the carrier gas to $\mathrm{H}_{2}$ is $80: 200$. The substrate temperature is about 650 and $600{ }^{\circ} \mathrm{C}$ at $1800 \mathrm{~W}$ and $1500 \mathrm{~W}$, respectively.

The surface morphology and element's distribution was characterized using a Tescan Vega 3(Czech Republic) scanning electron microscopy with EDS. The cross sectional sample was prepared by the conventional metallographic method. The details can be found in our previous publication [17]. The stress of diamond film and diamond phase 
composition was characterized by a Renishaw invia Reflex Raman spectroscopy using a $532 \mathrm{~nm}$ laser. The spot size is $\sim 2 \mu \mathrm{m}$. Raman image $(6 \times 6 \mu \mathrm{m})$ was carried out by scanning the sample in a raster pattern at an image resolution of $12 \times 12$ pixels (144 spectra). Phase identification of the film was characterized by grazing incidence X-ray diffraction (GIXRD) with incidence angle $2^{\circ}$ using a Bruker D8 Discover. Adhesion of film was assessed by Rockwell C indentation method using a load of $1470 \mathrm{~N}$.

\section{Results and discussion}

We firstly investigate the effects of growth time in the first step on the microstructure of diamond films. Fig. 1 shows SEM images of the diamond films deposited at $1800 \mathrm{~W}$ after different times. It is observed that there are comparatively sparse diamond particles with average size $\sim 100 \mathrm{~nm}$ on the surface after $10 \mathrm{~min}$ deposition. When the time increases to $19 \mathrm{~min}$, diamond particles become large and basically contact each other. But there are no particles observed on some concave places, as shown in the arrow of Fig. 1(b), which is attributed to high thermodynamic barriers on the concave sites [18]. After $25 \mathrm{~min}$, some local diamond film peels off, indicating a continuous diamond film cannot be obtained on the steel at $1800 \mathrm{~W}$.

In order to understand the reason, Raman mapping of the films were measured, as shown in Fig. 2. Each spectrum in the Raman mapping was deconvoluted to six peaks using Gaussian function, which are $~ 1130, ~ 1220, \sim 1332, \sim 1350, \sim 1460$ and $\sim 1580$ $\mathrm{cm}^{-1}$, respectively. The peaks at $\sim 1130$ and $\sim 1460 \mathrm{~cm}^{-1}$ are ascribed to transpoly-acetylene (TPA) existed in grain boundaries [19]. The peaks at $\sim 1350$ and 

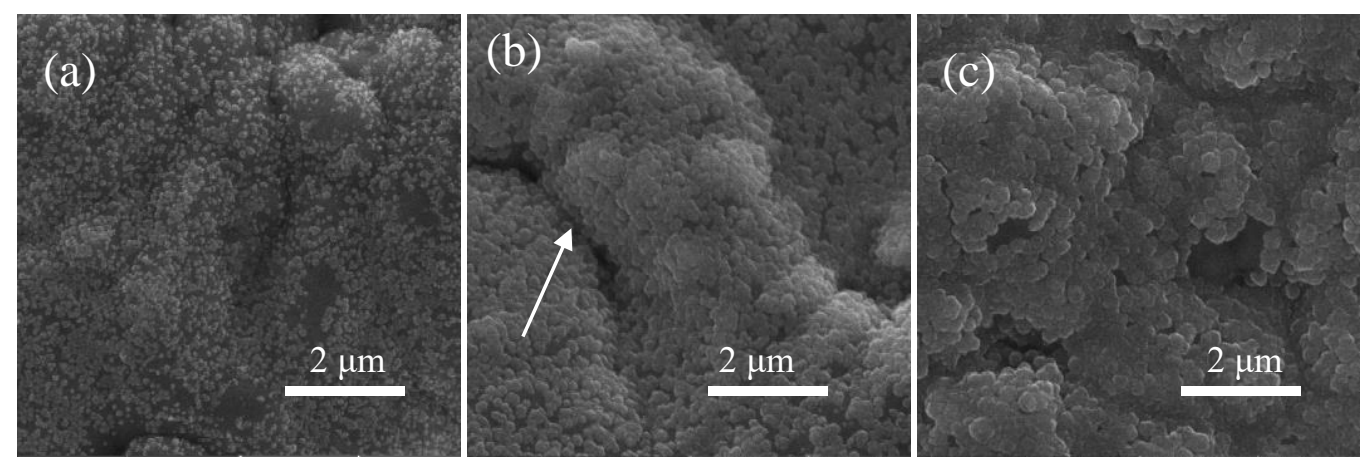

Fig.1 SEM images of diamond film deposited at $1800 \mathrm{~W}$ and after different time (a) $10 \mathrm{~min}$, (b) 19 $\min ,(c) 25 \min$

$\sim 1580 \mathrm{~cm}^{-1}$ correspond to D-band and G-band of $\mathrm{sp}^{2}$-bonded carbon, respectively. The peak at $\sim 1220 \mathrm{~cm}^{-1}$ is attributed to extremely small diamond grains or amorphous carbon [19]. The diamond peak position distribution and average Raman spectrum were displayed in the figure. It is observed that the diamond peak position of the diamond film after 10 min deposition is obviously smaller than that after $19 \mathrm{~min}$ deposition. The shift of diamond position from $1332 \mathrm{~cm}^{-1}$ is proportional to the stress. When the peak position is smaller than $1332 \mathrm{~cm}^{-1}$, the film shows the tensile stress. Otherwise, the film presents the compressive stress [20]. Therefore, the stress after 10 min deposition is compressive and it is obviously smaller than that after $19 \mathrm{~min}$ deposition. As there exits gaps between diamond particles after 10 min deposition, the diamond particle contracts easily during the cooling and the film shows low stress value. After 19 min deposition, the diamond particles join together and form the continuous film. As the diamond particle is difficult to contract during the cooling, the film shows large stress value. After 25 min deposition, due to the delamination of some local diamond films, the stress of the film releases mostly and shows low stress value. In addition, diamond content was calculated considering different Raman cross 
sections of diamond and non-diamond carbon [21]. The results are $71.1 \%, 58.8 \%$ and $64.6 \%$, respectively. Therefore, above results show that the growth time of about 10

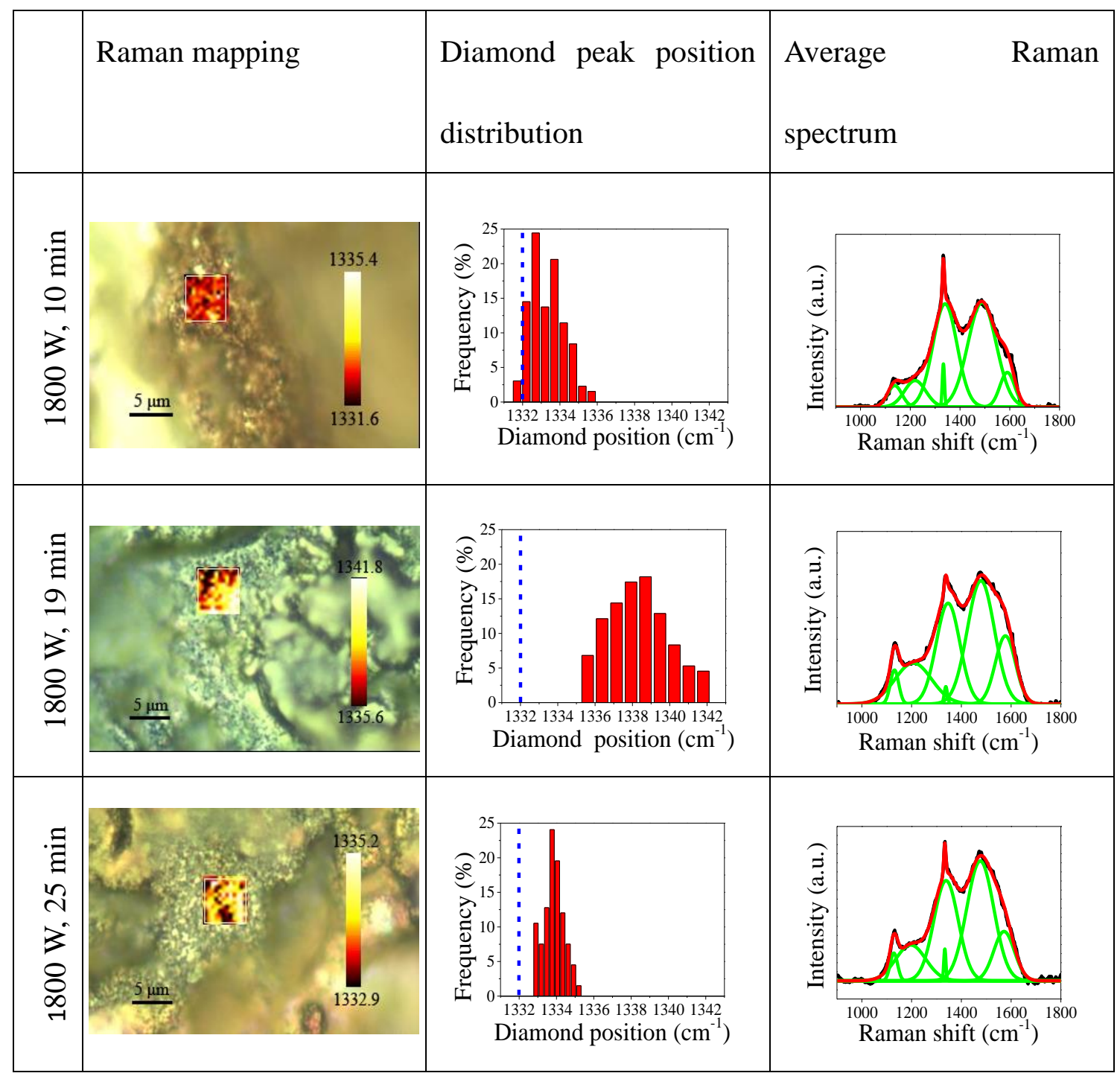

Fig.2 Raman mapping, diamond peak position distribution and average Raman spectrum of diamond film deposited at $1800 \mathrm{~W}$ for $10 \mathrm{~min}, 19 \mathrm{~min}$ and $25 \mathrm{~min}$, respectively.

min at high power of $1800 \mathrm{~W}$ prefers to prepare the isolated diamond particles with comparatively high diamond content and to decrease the internal stress.

In order to determine the appropriate power of second step, four samples at $1400-1700 \mathrm{~W}$ were deposited and the growth time is chosen as $10 \mathrm{~min}$. Fig. 3 shows their Raman spectra. Obvious diamond peaks are observed at 1500-1700 W, 
indicating that the diamond phase has been formed in this power range. However, no diamond peak but graphite peaks of 1350 and $1580 \mathrm{~cm}^{-1}$ is found at $1400 \mathrm{~W}$, which indicates that the diamond phase cannot be obtained at $1400 \mathrm{~W}$. So, the second step's power was chosen as $1500 \mathrm{~W}$ in order to obtain diamond phase.

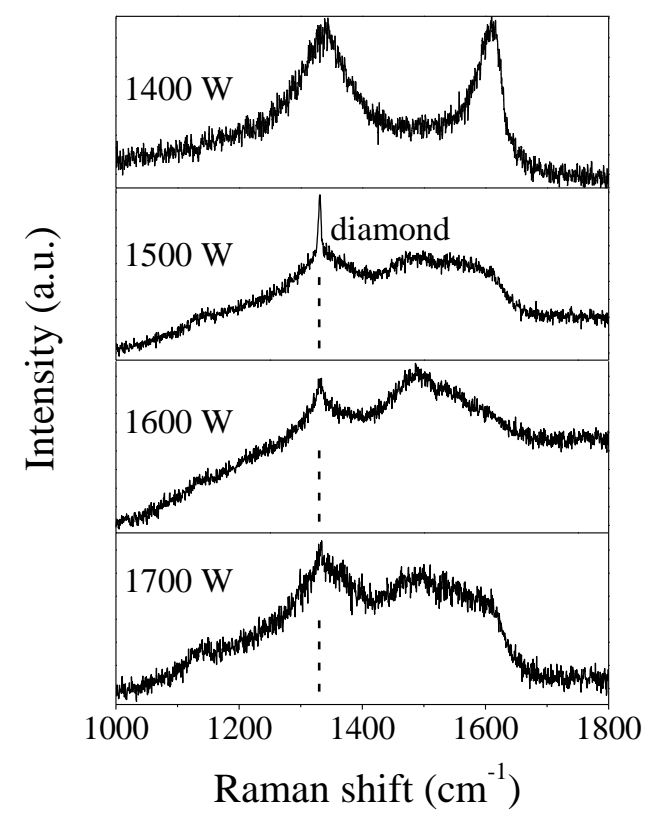

Fig. 3 Raman spectra of diamond films deposited at 1400-1700 W

In order to obtain a continuous diamond film with low stress, effects of different times in second step on the stress, phase composition and microstructure were studied. Fig. 4 shows the Raman mapping of the diamond films after different times in second step. It is observed that diamond peak positions for the samples growing for 20, 30, 60 and $90 \mathrm{~min}$ are all obviously smaller than that at first step for $19 \mathrm{~min}$. According to the relation between diamond peak shift and the stress as above mentioned, it is concluded that the magnitude of the stresses are obviously lower than that of the diamond film growing for $19 \mathrm{~min}$ in the first CVD process, indicating that the two-step dropped power process surely decreases the internal stress of the film. From Fig. 4, it is also observed that after $20 \mathrm{~min}$ and $30 \mathrm{~min}$ deposition, the diamond peak 


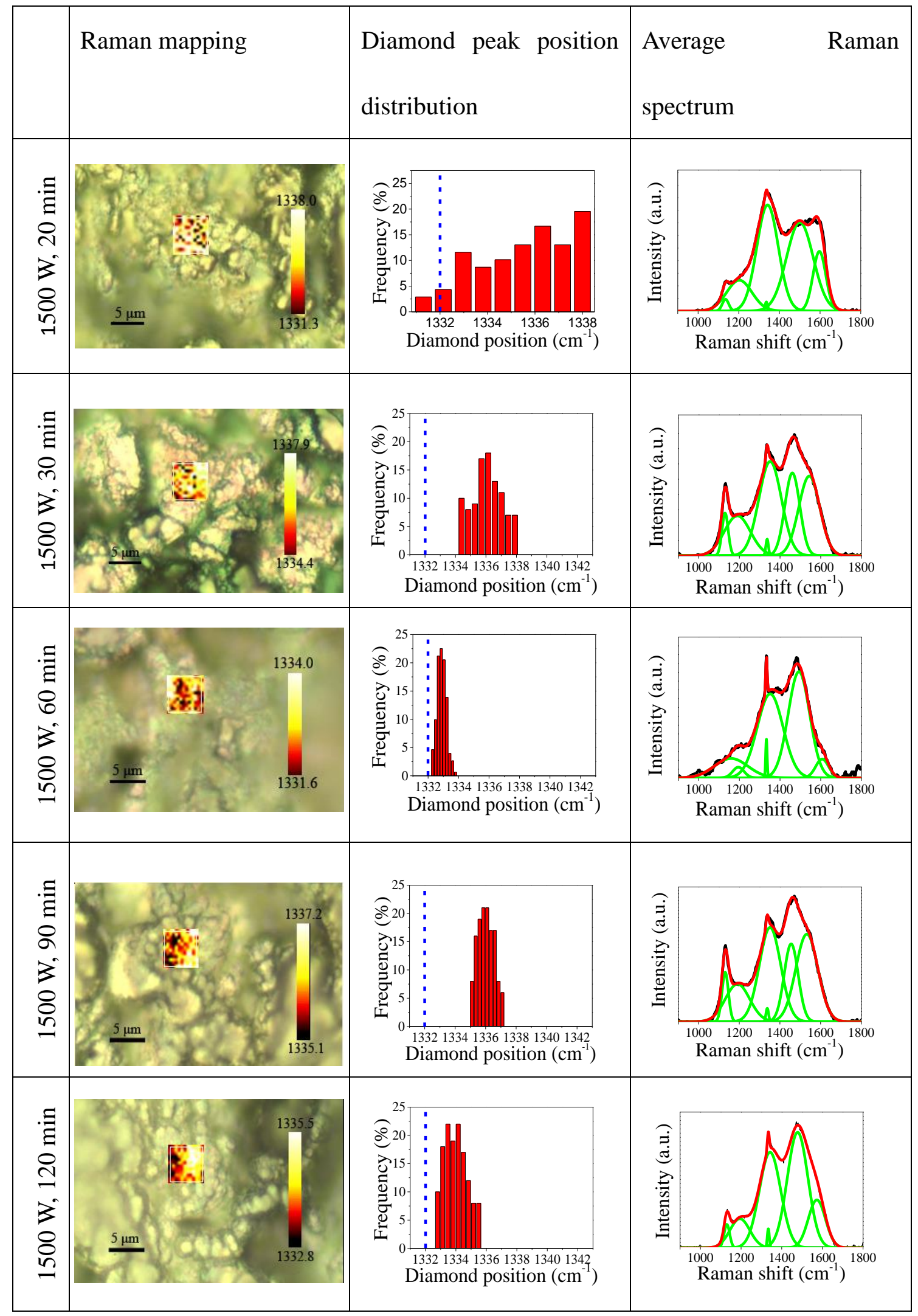

Fig. 4 Raman mapping, diamond peak distribution and average Raman spectrum of the diamond films at different times in second step 
position of diamond films is in the range of $1331.3-1338.0 \mathrm{~cm}^{-1}$. After $60 \mathrm{~min}$ deposition, the peak position obviously become small, it is in the range of 1331.6-1334.0 $\mathrm{cm}^{-1}$. After 90 min deposition, the peak position becomes large within the range of $1335.1-1337.2 \mathrm{~cm}^{-1}$. After $120 \mathrm{~min}$, the peak position becomes small again, within the range of $1332.8-1335.5 \mathrm{~cm}^{-1}$. This suggests that the stresses of the film deposited after $20 \mathrm{~min}$ and $30 \mathrm{~min}$ deposition are large and it becomes small after 60 min deposition. After 90 min deposition, the stress becomes large, while it was small again after 120 min. Diamond content was calculated and they are $46.3 \%$, $61.0 \%, 70.8 \%, 56.3 \%$ and $60.2 \%$ after second step deposition with the time of 20,30 , 60, 90 and $120 \mathrm{~min}$, respectively. Low diamond content after $20 \mathrm{~min}$ deposition is related to low power deposition. When the power is low, the filament temperature is low, the concentration of dissociated atomic hydrogen is low [22]. And the atomic hydrogen etches $\mathrm{sp}^{2}$ carbon faster than $\mathrm{sp}^{3}$ carbon. So, low concentration of atomic hydrogen leads to low content of the diamond. Diamond formation in CVD process involves a set of complex physical and chemical processes [23]. It is related to adsorption and diffusion of atoms, which is related to substrate materials. After the deposition time large than $30 \mathrm{~min}$, it is considered that new diamond phase forms on the diamond film due to homoepitaxial growth and the film presents comparatively high diamond content. Stress in diamond film generally includes thermal stress and intrinsic stress. Thermal stress is in relation to CTE mismatch between the stainless steel and the diamond film is compressive in general. Intrinsic stress is mainly related to the existence of nondiamond phase, defects, etc. Here, change of the stress is 
considered to be associated with change of the content of nondiamond phase, as the nondiamond phase is source of compressive intrinsic stress. When the content is higher, the value of intrinsic compressive stress is larger [24]. As mentioned above, when the deposition time increases from 20 to $60 \mathrm{~min}$, diamond content increases, i.e. nondiamond content decreases. So, the contribution of the compressive stress becomes smaller and the total stress becomes smaller with deposition time increasing from $20 \mathrm{~min}$ to $60 \mathrm{~min}$. After $90 \mathrm{~min}$, the contribution of compressive stress increases due to the increase of non-diamond content on one side. Also, thermal compressive stress becomes larger as the film becomes denser and thicker. As a result, the stress becomes large after $90 \mathrm{~min}$. The comparatively low stress after $120 \mathrm{~min}$ is attributed to the local spalling of the diamond film, as the delamination accommodates the stress.

Fig. 5 shows the SEM images of the diamond films after different second step's times. It is observed that a diamond film already forms on the surface after $20 \mathrm{~min}$ deposition, but some apertures between blocky structures (see the arrow indicating in Fig. 5(a)) can still be seen on the surface. Further, from the magnified image (i.e. Fig. $5(b))$, it is observed that no diamond particles exited in the aperture and some diamond particles do not contact each other on the surface. This indicates that the continuous diamond film is not obtained after $20 \mathrm{~min}$ growth. After $30 \mathrm{~min}$ deposition, the apertures almost cannot be observed on the surface of the film (as seen in Fig. 5(c)), diamond particles contact each other closely and a fully continuous diamond film forms on the surface (see the inset in Fig. 5 (c)). This suggests that the 
continuous diamond film forms at between 20 and 30 min. After 60 and 90 min deposition, the film is still continuous and no delaminated area can be found on the

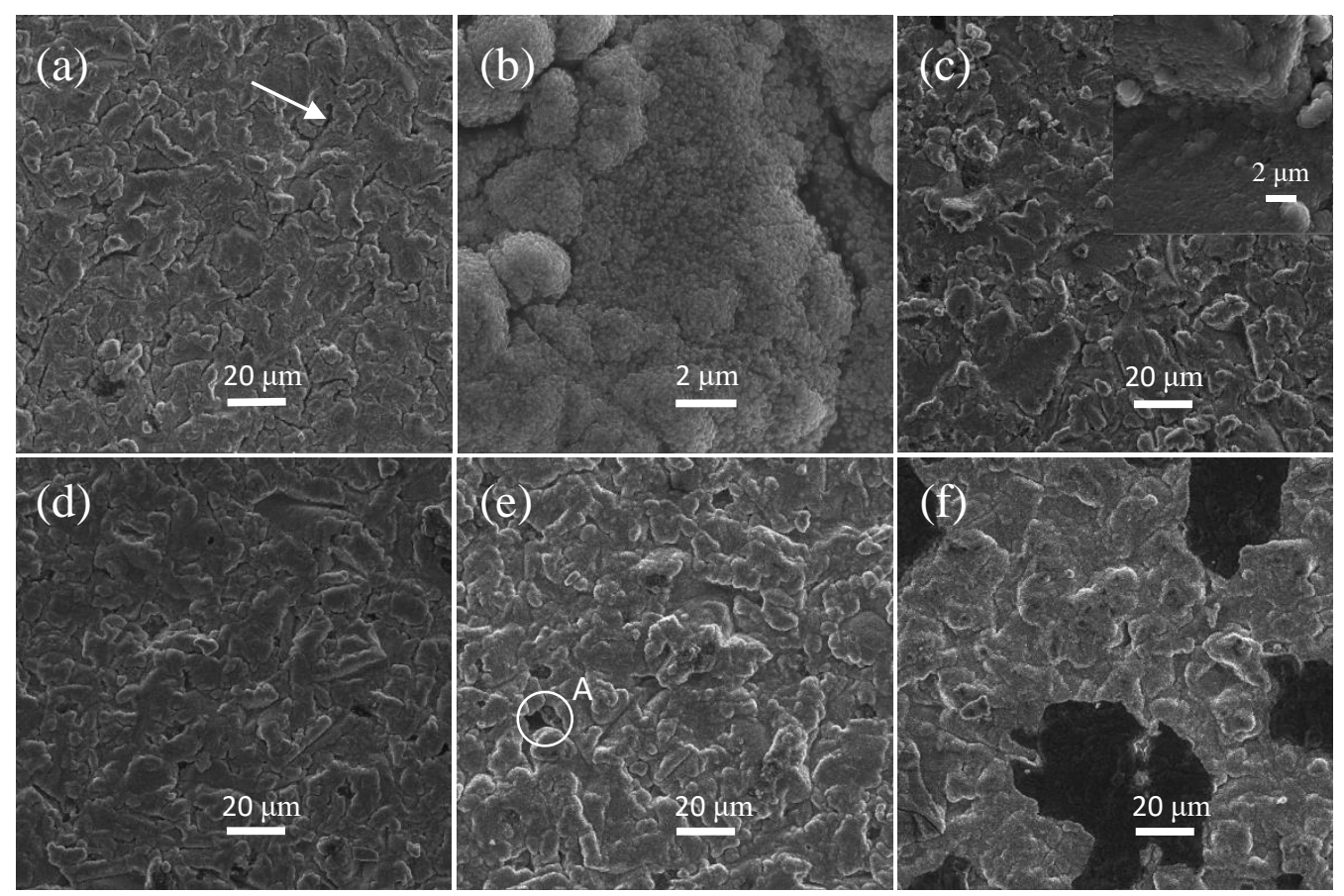

Fig. 5 SEM images of diamond films deposited after second step time (a) 20 min (low magnification), (b) $20 \mathrm{~min}$ (high magnification), (c) $30 \mathrm{~min}$, (d) $60 \mathrm{~min}$, (e) $90 \mathrm{~min}$, and (f) 120 min. The inset of (c) shows the corresponding magnified image.

surface, as shown in Fig.5 (d) and (e). But some tiny amounts of pores (e.g. circle A in Fig. 5(e)) are observed on the surface. After $120 \mathrm{~min}$, some local diamond film flakes off, indicating that the continuous diamond film only can be obtained at between 90 $\min$ and $120 \mathrm{~min}$.

Fig. 6 (a) shows GIXRD of the sample after second step time $60 \mathrm{~min}$. It is observed that the film is composed of a large amount of $(\mathrm{Cr}, \mathrm{Ti}, \mathrm{Al}) \mathrm{N}$ and $(\mathrm{Cr}, \mathrm{Ti}, \mathrm{Al})_{2} \mathrm{~N}$ phase and a small quantity of $\mathrm{Cr}_{2} \mathrm{C}_{3}$ phase. The appearance of the carbide phase suggests that the interlayer is a little carburized, chemical bonding at the interface between diamond film and the interlayer is formed. Fig. 6 (b) shows EDS line scan of the 
sample. It is observed that the thicknesses of the diamond film and the interlayer are $\sim 0.4$ and $1.7 \mu \mathrm{m}$, respectively. And nitrogen content is still high in the interlayer, proving the low extent of carburization of the interlayer again. From the line scan, it is
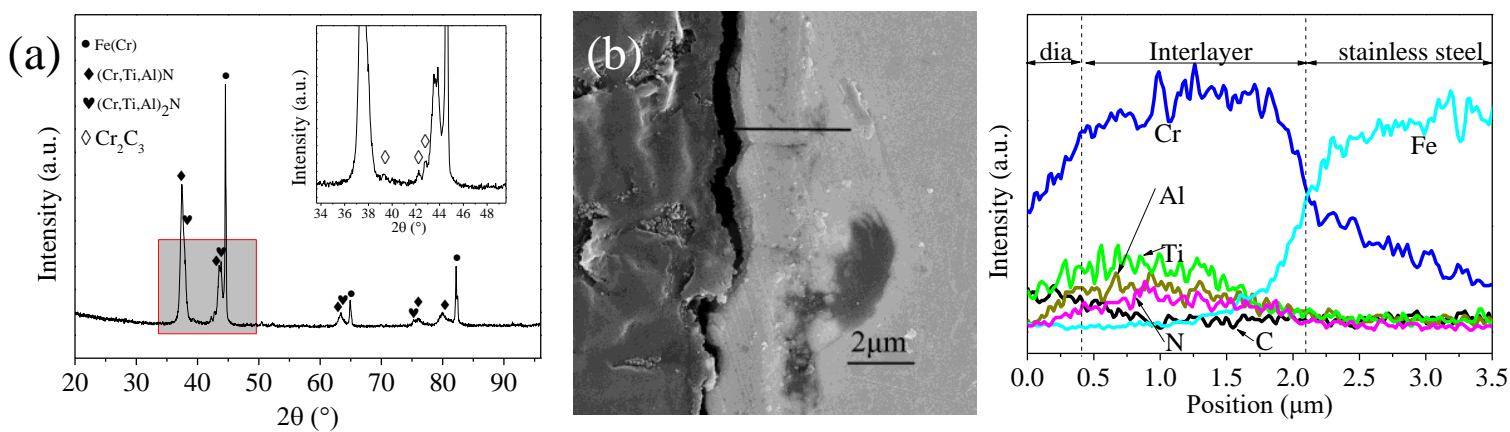

Fig. 6 GIXRD (a) and EDS line scan (b) of the sample after second step time $60 \mathrm{~min}$ also observed that iron element does not diffuse out the interlayer and carbon element does not diffuse into the steel, indicating that the interlayer effectively block $\mathrm{C}$ inward diffusion and $\mathrm{Fe}$ outward diffusion. Compared to carburization extent of the $\mathrm{Cr} / \mathrm{CrN}$ interlayer in our previous work [17], the extent is obviously small. In general, when the deposition temperature is low, the extent of carbon reaction is low. Also, the existence of aluminum element in the interlayer enhances the nucleation rate [9], alleviates carbon reaction's extent. Therefore, it is believed that the low carburization extent is related to low power deposition in the two-step process and the existence of aluminum element in the interlayer.

Fig. 7 shows Rockwell indentation morphology of the films after different second step times. It is observed that there is basically no chipping or cracking on the border of the indentation on the film after 20 min deposition, meaning that the film has good adhesion. There are some chippings on the border of the indentation on the film after 30 min deposition. There are more chippings on the border and some local flaking 
areas are also observed on the periphery of the film after 60 min deposition. And more flaking areas are observed on the film after 90 min deposition. This suggests that the adhesion become poor as second step time increases. The composition of the

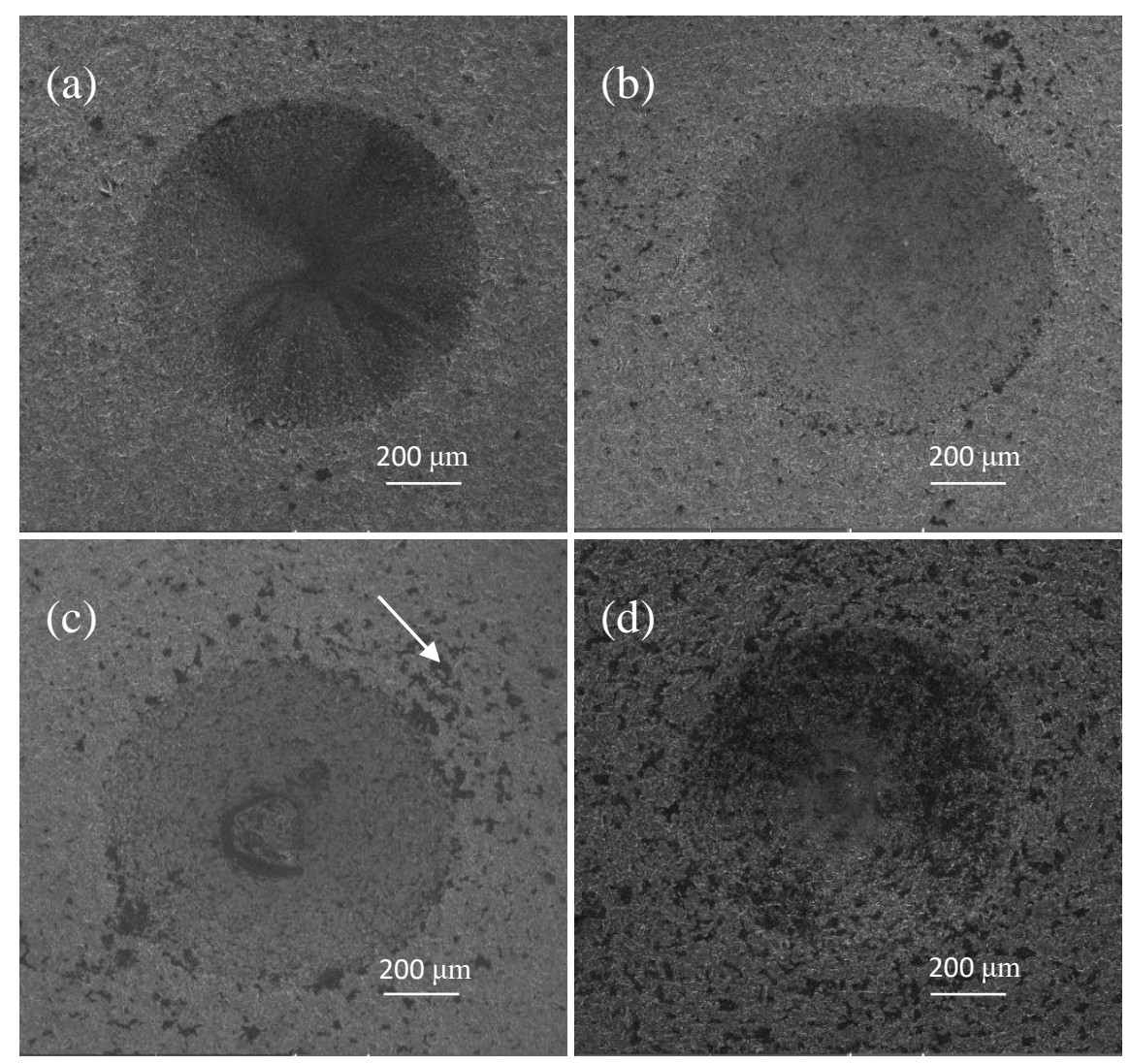

Fig. 7 Rockwell indentation morphology of the films after different second step times (a) 20 min (b) $30 \min (\mathrm{c}) 60 \min (\mathrm{d}) 90 \mathrm{~min}$

delaminated area (for example, the arrow indicates in Fig. 7(c)) was tested using the EDS. The results show that the residual film includes 15.9 wt.\% C, $25.1 \mathrm{wt} . \% \mathrm{~N}, 3.1$ wt.\% Al, 5.2 wt. $\% \mathrm{Ti}, 49.9$ wt. $\% \mathrm{Cr}, 0.6$ wt.\%Fe, indicating that the interlayer doesn't peel off from the substrate. This means that the adhesion between the interlayer and the stainless steel is good. The weakest place in the film is interlayer/diamond interface. The film after $20 \mathrm{~min}$ deposition does not chip, as the isolated diamond particles deform freely when the indenter is pressed into the sample. The diamond film after 30 min deposition becomes continuous, and the film's deformation is 
restrained in the indenting process. As a result, some areas of the film on the border peel off. The film after $60 \mathrm{~min}$ deposition is vulnerable to fracture and peels off in the indenting process due to the increase of diamond content and thickness, so that more delamination areas are found. More peeled areas are observed on the film after $90 \mathrm{~min}$ deposition, as the stress and thickness all become large.

Above results show that low-stress diamond films can be prepared on $3 \mathrm{Cr} 13$ steel using the two-step dropped power process. Fig. 8 shows the stress relief mechanism of diamond film deposited in the two-dropped power process. As seen, diamond particles are firstly randomly formed on the interlayer's surface at first step (i.e. at high power). Then the power is decreased quickly to the low power. Deposition temperature is high (low) at high (low) power. Thermal stress arising from temperature change from high power to low power can mostly be released, as the discrete diamond particles contract freely. As above mentioned, the substrate temperature is 650 and $600{ }^{\circ} \mathrm{C}$ at 1800 and $1500 \mathrm{~W}$, respectively. CTEs of stainless steel and diamond are $17.8 \times 10^{-6}$ and $1 \times 10^{-6}$, respectively. Assuming that thermal stress arising from the temperature decrease is released, it is estimated that the stress decreases by $7.7 \%$ according to the thermal stress equation [17].Then the continuous diamond film with blocky structure was formed on the rough interlayer's surface at low power. Singh R K's study showed that rough surface decreased the stress [25]. So it is considered that the blocky structure is beneficial to the release of the stress. In addition, it is considered that some amount of pores exited in the film also contribute to the accommodation of stress, as it can offer more spaces to shrink. As a result, the 
stress in the film is small.

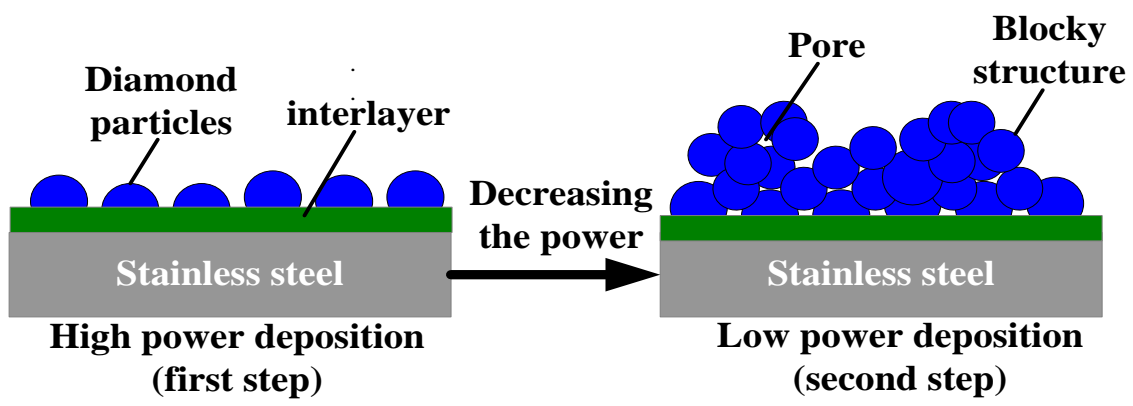

Fig. 8 stress relief mechanism of a two-step dropped power process

\section{Conclusions}

A continuous diamond films has successfully been deposited on stainless steel with a $\mathrm{Cr} / \mathrm{CrN} / \mathrm{CrTiAlN}$ interlayer using a new two-step dropped power process. In the first step, isolated diamond particles are deposited on the interlayer at high power $1800 \mathrm{~W}$ for $10 \mathrm{~min}$. As the discrete particles contract freely, thermal stress arising from high power to low power is mostly released. Subsequently, the continuous diamond film is deposited at low power $1500 \mathrm{~W}$, which further decreases the thermal stress. In addition, the formed blocky microstructure and a small quantity of pores in the two-step process also contribute to stress accommodation. As a result, the film shows lower stress compared to the continuous film deposited only in the first step. This work provides a new way to prepare low-stress diamond films on stainless steel.

\section{Acknowledgments}

This research was supported by International science technology cooperation program of China (No. 2014DFR51160), Zhejiang provincial natural science foundation (No. LY18E020013), National key research and development program of China (No. 2016YFE0133200), European union's horizon 2020 research and 
innovation staff exchange scheme (No. 734578) and Xinmiao talents program of zhejiang province (No. 2016R403060).

\section{References}

[1] X. C. Wang, X. T.Shen, T. Q. Zhao, F. H. Sun, B. Shen, Tribological properties of SiC-based MCD films synthesized using different carbon sources when sliding against $\mathrm{Si}_{3} \mathrm{~N}_{4}$, Appl. Surf. Sci. 369(2016) 448-459.

[2] V. Kundrát, X. L. Zhang, K. Cooke, H. L. Sun, J. Sullivan, H. T. Ye, A novel Mo-W interlayer approach for CVD diamond deposition on steel, AIP Adv.5 (2015) 047130-047138.

[3] J. G. Buijnsters, M. Tsigkourakos, T. Hantschel, F. O. V. Gomes, T. Nuytten, P. Favia, H. Bender, K. Arstila, J. P. Celis, W. Vandervorst, Effect of boron doping on the wear behavior of the growth and nucleation surface of micro- and nanocrystalline diamond films. Acs Appl. Mat. Interfaces. 8(2016)26381-26391.

[4] X. Sun, H. T. Ma, L. Z. Yang, M. Sanchez-Pasten, D. Craig Penner, Y. S. Li, Q. Yang, Metal dusting, carburization and diamond deposition on $\mathrm{Fe}-\mathrm{Cr}$ alloys in $\mathrm{CH}_{4}-\mathrm{H}_{2}$ plasma atmospheres, Corros. Sci. 98(2015)619-625.

[5] X. J. Li, L. L. He, Y. S. Li, Q. Yang, A, Hirose. TEM interfacial characterization of CVD diamond film grown on Al inter-layered steel substrate, Diam. Relat. Mater. 50(2014)103-109.

[6] A. Contin, K. A. Alves, R. A. Campos, G. D. Vasconcelos, D. D. Damm, V. J. Trava-Airoldi, E. J. Corat, Diamond films on stainless steel substrates with an interlayer applied by laser cladding, Mater. Res, 20(2017)543-548. 
[7] J. G. Buijnsters, P. Shankar, W. Fleischer, W. J. P. Enckevort, J. J. Schermer, J. J. Meulen, CVD diamond deposition on steel using arc-plated chromium nitride interlayers, Diam. Relat. Mater. 11(2002)536-544.

[8] Q. H. Fan, J.Grácio, E. Pereira, N. Ali, W. Ahmed, Study of diamond adhesion behavior on chromium and titanium for obtaining adherent diamond coatings on steel, J. Mater. Res. 15(2000)2330-2335.

[9] Y. S. Li, Y. Tang, Q. Yang, C. Xiao, A. Hirose, Diamond deposition on steel substrates with an Al interlayer, Int. J. Refract. Met. H. 27(2009)417-420.

[10]Y. S. Li, Y. Tang, Q. Yang, J. Maley, R. Sammynaiken, T. Riger, C. Xiao, A. Hirose, Ultrathin W-Al dual interlayer approach to depositing smooth and adherent nanocrystalline diamond films on stainless steel, ACS Appl. Mat. interfaces. 2(2010)335-338.

[11]X. Sun, Y. Li, B. Wan, L. Z. Yang, Q. Q. Yang, Deposition of diamond coatings on Fe-based substrates with $\mathrm{Al}$ and $\mathrm{Al} / \mathrm{AlN}$ interlayers, Surf. Coat. Technol. 284(2015)139-144.

[12]O. Glozman, G. Halperin, I. Etsion, A. Berner, D. Shectman, G. H. Lee, A. Hoffman, Study of the wear behavior and adhesion of diamond films deposited on steel substrates by use of a $\mathrm{Cr}-\mathrm{N}$ interlayer, Diam. Relat. Mater. 8(1999)859-864.

[13]M. Chandran, A. Hoffman, Diamond film deposition on WC-Co and steel substrates with a $\mathrm{CrN}$ interlayer for tribological applications, J. Phys. D. Appl. Phys, 49(2016)213002-213026. 
[14]J. Ballinger, S. A. Catledge, Metal-boride interlayers for chemical vapor deposited nanostructured NSD films on 316 and 440C stainless steel, Surf. Coat. Technol. 261(2015)244-252.

[15]A. Contin, G. D. Vasconcelos, D. M. Barquete, R. A. Campos, V. J.Trava-Airoui, E. J. Corat, Laser cladding of SiC multilayers for diamond deposition on steel substrates, Diam. Relat. Mater. 65(2016)105-114.

[16]S. Yang, D. G. Teer, Properties and performance of CrTiAlN multilayer hard coatings deposited using magnetron sputter ion plating, Surf. Eng. 18(2002)391-396.

[17]X. Li, J. S. Ye, H. C. Zhang, T. Feng, X. J. Hu, Sandblasting induced stress release and enhanced adhesion strength of diamond films deposited on austenite stainless steel, Appl. Surf. Sci. 412(2017)366-373.

[18]B. Zhang, L. Y. Zhou, Effect of sandblasting on adhesion strength of diamond coatings, Thin Solid Films 307(1997)21-28.

[19]K, Huang, X. J. Hu, H. Xu, Y. G. Shen, A. Khomich, The oxidization behavior and mechanical properties of ultrananocrystalline diamond films at high temperature annealing, Appl. Surf. Sci. 317(2014) 11-18.

[20]V. G. Ralchenko, A. A. Smolin, V. G. Pereverzev, E. D. Obraztsova, K. G. Korotoushenko, V. I. Konov, Yu. V. Lakhotkin, E. N. Loubnin, Diamond deposition on steel with CVD tungsten intermediate layer, Diam. Relat. Mater. $4(1995) 754-758$.

[21]S. R. Sails, D. J. Gardiner, M. Bowden, J. Savage, D. Rodway, Monitoring the 
quality of diamond films using Raman spectra excited at $514.5 \mathrm{~nm}$ and $633 \mathrm{~nm}$, Diam. Relat. Mater. 5(1996) 589-591.

[22]D. Uger, A. J. Storm, R. Erberk, Quantification of the atomic hydrogen flux as a function of filament temperature and $\mathrm{H}_{2}$ flow rate, J. Vac. Sci. Technol A, 30(2013)031603-031606.

[23]P.W. May, Diamond thin films: a $21^{\text {st }}$-century material, Phil. Trans. R. Soc. Lond A, 358(2000)473-495.

[24]T. Liu, H. Pinto, P. Brito, L. A. Sales, D. Raabe. Residual stress analysis in chemical-vapor-deposition diamond films. Appl. Phys. Let. 94(2009) 201902-201903.

[25]D. G. Lee, D. R. Gilbert, S. M. Lee, R. K. Singh, Surface composites: a novel method to fabricate adherent interfaces in thermal-mismatched systems, Compos: Part B-Eng. 30(1999)667-674. 